\title{
Erratum to: Serological makers of rubella infection in Africa in the pre vaccination era: a systematic review
}

\author{
Mariam M. Mirambo ${ }^{1 *}$, Mtebe Majigo ${ }^{2}$, Said Aboud ${ }^{2}$, Uwe Groß ${ }^{3}$ and Stephen E. Mshana ${ }^{1}$
}

\section{Erratum to: BMC Res Notes (2015) 8:716 DOI 10.1186/s13104-015-1711-x}

Unfortunately the original version of this article [1] contained an incorrect reference.

Reference number 45 was a duplicate of reference number 43. This should have read:

Adam O, Makkawi T, Kannan A, Osman ME. Seroprevalence of rubella among pregnant women in Khartoum state, Sudan. East Mediterr Health J 2013;19:812-15.

\section{Author details}

${ }^{1}$ Department of Microbiology and Immunology, Weill Bugando School of Medicine, Catholic University of Health and Allied Sciences, P.O. Box 1464 Mwanza, Tanzania. ${ }^{2}$ Department of Microbiology and Immunology, Muhimbili University of Health and Allied Sciences, P.O. Box 65001, Dar es Salaam, Tanzania. ${ }^{3}$ Institute of Medical Microbiology, University Medical Centre Göettingen, Göttingen, Germany.

The online version of the original article can be found under doi:10.1186/s13104-015-1711-x.

Received: 14 June 2016 Accepted: 16 June 2016

Published online: 05 July 2016

\author{
Reference \\ 1. Mirambo MM, Majigo M, Aboud S, Groß U, Mshana SE. Serological mak- \\ ers of rubella infection In Africa in the pre vaccination era: a systematic \\ review. BMC Res Notes. 2015;8:716. doi:10.1186/s13104-015-1711-x.
}

*Correspondence: mmmirambo@gmail.com

${ }^{1}$ Department of Microbiology and Immunology, Weill Bugando School

of Medicine, Catholic University of Health and Allied Sciences,

P.O. Box 1464, Mwanza, Tanzania

Full list of author information is available at the end of the article provided you give appropriate credit to the original author(s) and the source, provide a link to the Creative Commons license, and indicate if changes were made. The Creative Commons Public Domain Dedication waiver (http://creativecommons.org/ publicdomain/zero/1.0/) applies to the data made available in this article, unless otherwise stated. 